\title{
Temáticas prioritárias no campo de gênero e ciências no Brasil:
}

raça/etnia, uma lacuna?*

\author{
Luzinete Simões Minella**
}

\section{Resumo}

Este artigo tem como objetivos: a) elaborar um balanço das temáticas abordadas em diferentes estudos representativos da área de gênero e ciências, no Brasil, identificando aquelas que têm prevalecido; b) refletir sobre avanços e lacunas, indagando até que ponto as análises recuperam as interseções entre gênero $e$ raça/etnia. Foram analisadas várias contribuições representativas da área concluindo-se que as temáticas podem ser classificadas em três grandes tendências. Apesar dos avanços representados pelo conjunto dessas contribuições, avalia-se ainda que a ênfase recai sobre as assimetrias entre homens e mulheres; as pesquisas empíricas contemplam com certa frequência as interseções entre gênero e gerações, através da análise de dados agregados por faixa etária; em algumas pesquisas há informações sobre o perfil socioeconômico das mulheres analisadas; não foram encontradas análises que coloquem as questões raciais e étnicas no centro do debate, constituindo-se essa lacuna num grande desafio epistemológico e político.

Palavras-chave: Gênero, Ciências, Temáticas Prioritárias, Interseções.

\footnotetext{
* Recebido para publicação em 16 de janeiro de 2011, aceito em 9 de fevereiro de 2012.

** Professora do Programa de Pós-Graduação Interdisciplinar em Ciências Humanas da Universidade Federal de Santa Catarina. Pesquisadora do Instituto de Estudos de Gênero da UFSC.luzinete@matrix.com.br
}

cadernos pagu (40), janeiro-junho de 2013:95-140. 
Temáticas prioritárias no campo de gênero e ciências no Brasil

Fundamental Thematic in Gender and Sciences in Brazil: Race/Ethnics, is There a Lack?

\begin{abstract}
This article reflects on the Gender and Sciences in Brazil, aiming at: a) estimating and identifying the predominant thematics approached in different representative studies of the area; b) reflecting on the advances and gaps, observing to which extent the analyses recuperate the intersections between gender and race/ethnicity. Several representative contributions were analyzed, and it was possible to classify the thematic into three great tendencies. Despite the advances represented by such set of contributions, it is also observed that the emphasis has been mostly on the asymmetries between men and women; the empirical research has contemplated, with certain frequency, the intersections between gender and generations through the analysis of data comprehended by age; in some research, it is possible to find information on the social-economical profile of the women under study; analyses that bring the racial and ethnic question to the center of the debate have not been found, turning this lack into a great epistemological and political challenge.
\end{abstract}

Key Words: Gender, Sciences; Fundamental Thematic, Intersections. 


\section{Introdução}

Este artigo reflete sobre as relações entre gênero e ciências no Brasil, tendo em vista dois objetivos: elaborar um balanço das temáticas abordadas em diferentes estudos representativos da área, identificando aquelas que têm prevalecido e refletir sobre avanços e lacunas, indagando até que ponto as análises recuperam as interseções entre gênero e raça/etnia.

A abordagem teórica se insere no âmbito dos estudos de gênero e das teorias feministas e considera que a ciência tem se constituído ao longo do tempo como um campo de disputas no qual se entrelaçam diferentes "eixos de subordinação". Ao mesmo tempo, reconhece que a participação das mulheres no campo científico aumentou gradativamente, sendo bastante expressiva em certas áreas científicas, conforme apontam vários dos estudos que serão analisados mais adiante.

A revisão da literatura empreendida até o momento evidencia que os temas tratados nesse campo podem ser classificados em três tendências temáticas que serão apresentadas $e$ discutidas no quinto item deste artigo.

As questões centrais que norteiam as reflexões resultam de algumas inquietações teóricas surgidas na medida em que foram aprofundadas as leituras na área e podem ser assim resumidas: no caso da produção nacional, quais os temas abordados com maior frequência? Em que medida as pesquisas realizadas enfatizariam as interseções gênero e raça/etnia, bem como as interferências, entrelaçamentos e sobreposições desses eixos com outros marcadores da diferença? Como explicar o tratamento dado a essas sobreposições ou sua invisibilidade? Parto, portanto, da compreensão das interseções como aspecto fundamental para ampliar o debate sobre o tema. Nas considerações finais, levanto algumas hipóteses sobre essas questões, a respeito das quais pretendo continuar a dialogar e a refletir.

Entendo interseccionalidade nos termos propostos por Kimberlé Creenshaw (2002), ou seja, como "associação de 
Temáticas prioritárias no campo de gênero e ciências no Brasil

sistemas múltiplos de subordinação" que "tem sido descrita de vários modos: discriminação composta, cargas múltiplas, ou como dupla ou tripla discriminação". Segundo a autora,

a interseccionalidade é uma conceituação do problema que busca capturar as conseqüências estruturais e dinâmicas da interação entre dois ou mais eixos da subordinação. Ela trata especificamente da forma pela qual o racismo, o patriarcalismo, a opressão de classe e outros sistemas discriminatórios criam desigualdades básicas que estruturam as posições relativas de mulheres, raças, etnias, classes $e$ outras. Além disso, a interseccionalidade trata da forma como ações e políticas específicas geram opressões que fluem ao longo de tais eixos, constituindo aspectos dinâmicos ou ativos do desempoderamento (Creenshaw, 2002:177).

Observo, inicialmente, que este estudo também se inspira em outras literaturas, uma das quais está representada pela interpretação de Pierre Bourdieu (1983) sobre o campo científico como lugar de tensões e antagonismos, indutor e reprodutor de desigualdades. De acordo com o autor,

o campo científico é sempre o lugar de uma luta, mais ou menos desigual, entre agentes desigualmente dotados de capital específico e, portanto, desigualmente capazes de se apropriarem do produto do trabalho científico que o conjunto dos concorrentes produz pela sua colaboração objetiva ao colocarem em ação o conjunto dos meios de produção científica disponíveis (Bourdieu, 1983:136).

$\mathrm{O}$ autor destaca os conflitos entre novatos e veteranos. Sem dúvida, seus pontos de vista sobre as hierarquias geracionais representam um avanço no sentido da desconstrução de uma visão mistificada do campo científico. Mas, ao elaborar este texto, através de um enfoque feminista atento às interseções, parto do pressuposto de que as ciências se constituem como um campo de 
disputas mais amplas que envolvem também as clivagens de gênero, classe e etnia, embora essas nem sempre sejam enfatizadas.

\section{Caminhos da pesquisa: a intenção e seus limites}

Minha intenção consiste em elaborar um balanço dos estudos realizados pelas pesquisadoras brasileiras que fazem uma crítica às ciências a partir das reflexões sobre a exclusão e a inserção das mulheres nos distintos campos disciplinares e que à exemplo das teóricas do "centro", se interrogam a respeito da participação das mulheres no campo científico e do impacto do feminismo sobre a ciência. ${ }^{1}$

A metodologia da pesquisa se fundamentou num levantamento bibliográfico representativo, embora não exaustivo. A elaboração da classificação das tendências temáticas prioritárias se baseou na consulta de 78 estudos sobre o tema, publicados em periódicos científicos feministas, anais de congressos e livros, dentre eles algumas obras de referência organizadas, a partir dos anos noventa. A opção por esses periódicos tem suas limitações, pois deixa de fora muitas das contribuições importantes divulgadas em outros veículos, algumas das quais serão brevemente mencionadas no terceiro item. Outras serão contempladas em estudos posteriores juntamente com teses $e$ dissertações defendidas no mesmo período. ${ }^{2}$ Dadas essas lacunas,

${ }^{1}$ Vale ressaltar que, mais recentemente, as pesquisas na área têm sido estimuladas através de várias políticas públicas alavancadas pela Secretaria de Políticas para as Mulheres, entre as quais destaco o Programa Mulher e Ciência (www.spm.gov.br e www.cnpq.br).

${ }^{2}$ Entre as publicações que serão analisadas em etapas futuras da pesquisa, encontram-se artigos do vol. 15, Suplemento 0, da Revista História, Ciências, Saúde - Manguinhos, de 2008, organizado por Nara Azevedo, Luís Octavio Ferreira, Maria Margaret Lopes e Bianca Antunes Cortes. Neste estudo nos referimos apenas ao artigo de Ferreira et alii. Também serão contempladas, entre outras, várias das relevantes pesquisas realizadas por Maria Lúcia Mott (2007; 2008a e 2008b). 
Temáticas prioritárias no campo de gênero e ciências no Brasil

entendo que seus resultados constituem apenas um esboço de um quadro geral das temáticas, estando sujeitos a revisões posteriores.

De modo geral, o levantamento bibliográfico feito até o momento mostra que os estudos do campo Gênero e Ciências no Brasil foram e continuam sendo influenciados por algumas obras de referência, produzidas no contexto anglo-saxão a partir dos anos oitenta, nas quais são encontradas as críticas fundamentais das epistemologias feministas à ciência. Podemos citar, por exemplo, a coletânea organizada por Nancy Tuana, Feminism and Science (Race, Gender and Science), publicada em 1989, incluindo artigos de várias teóricas feministas, tais como, Evelyn Fox Keller, Helen Longino, Sandra Harding, Luce Irigarai, etc. Outra coletânea, organizada por Evelyn Fox Keller e Helen Longino, Feminism and Science foi publicada na década seguinte, com artigos das organizadoras e de Donna Haraway, Sandra Harding, Mary Tiles, Carol Cohn, Naomi Scheman, entre outras.

Ainda no âmbito das obras clássicas, destacam-se também as influências das reflexões de Donna Haraway sobre o ciborgue (1994) e sobre os "saberes localizados" (1995); os questionamentos de Sandra Harding sobre os fundamentos da filosofia da ciência tradicional (1996) e os achados de Londa Schiebinger (2001) em torno dos efeitos do feminismo sobre o conteúdo do conhecimento científico, focalizando o gênero no cerne da medicina, da primatologia, arqueologia, biologia, física e matemática.

Os estudos de Maria Margaret Lopes, uma das pioneiras do campo de Gênero e Ciências no Brasil, proporcionam uma visão geral dos debates. Lopes (2006a) se refere, dentre outras, à importância das contribuições de Evelyn Fox Keller, assinalando que essa autora sintetizou as nuances históricas e políticas desse campo, referindo-se a "três linhas de investigação que teriam prevalecido nos anos noventa: mulheres na ciência, construções científicas de gênero $e$ influência do gênero nas construções 
históricas da ciência. ${ }^{3 "}$ De acordo com Lopes, posteriormente, a partir das análises sobre a expansão do campo, Fox Keller observaria sua diversificação $e$ suas novas mutações, paralelamente à persistência de um denominador comum: "sua ativa resistência ao desaparecimento do gênero (e, é claro das mulheres)" (Lopes, 2006a:41).

$\mathrm{Na}$ última parte deste artigo, ao tentar sintetizar o mapeamento das tendências temáticas da área no Brasil, voltarei a me referir a algumas dessas autoras. Os diferentes itens do texto, na medida do possível, tentam obedecer ao critério cronológico. Nos primeiros, abordo a emergência e a consolidação do campo, focalizando os vários temas tratados nas pesquisas divulgadas em três veículos que alavancaram os debates na área: os Cadernos Pagu, publicação do Núcleo de Estudos de Gênero da Universidade Estadual de Campinas (Unicamp); os Cadernos de Gênero e Tecnologia, do Grupo de Estudos e Pesquisas sobre Relações de Gênero e Tecnologia (GeTec) do Centro Federal de Educação Tecnológica (CEFET/Paraná); e a Revista Tecnologia e Sociedade do Programa de Pós-Graduação em Tecnologia (PPGTE) da Universidade Tecnológica Federal do Paraná (UTFPr). Também serão referidos estudos publicados em outras fontes, incluindo a Revista Estudos Feministas.

Em seguida, relaciono alguns dos livros e coletâneas que entraram em cena paralelamente à diversificação temática $e$ institucional observada nos periódicos científicos citados anteriormente. No balanço final, depois de agrupar os estudos conforme os temas predominantes, elaboro alguns comentários críticos e relaciono algumas recomendações gerais no intuito de subsidiar as políticas científicas e as pesquisas na área.

${ }^{3}$ Nesse fragmento, Lopes se refere às seguintes obras: Secrets of Life, Secrets of Death: essays on language, gender and science (1992) e The Origin, History, and Politics of the Subject Called "Gender and Science" (1995), de Evelyn Fox Keller. 
Temáticas prioritárias no campo de gênero e ciências no Brasil

A respeito da emergência dos estudos sobre gênero e ciência no país, Hildete Pereira de Melo e André Barbosa Oliveira afirmam que

desde os anos 1970, com a segunda onda feminista do século XX, esta temática também ressoou no Brasil, no início, com as pesquisadoras da Fundação Carlos Chagas, espalhando-se, posteriormente, no meio acadêmico com a consolidação de vários núcleos de estudos de gênero. Particularmente o tema gênero e ciência ganhou relevância nos anos 1990, com destaque para estudos dos grupos da Unicamp, Fiocruz, NEIM/UFBA e tantas outras pesquisadoras individuais que analisam a ausência das mulheres da História da Ciência no Brasil (Melo e Oliveira, 2006:301-331).

Os artigos publicados pela Fundação Carlos Chagas nos anos setenta representaram um dos marcos iniciais no desenvolvimento do tema. Dois deles, a meu ver, ilustram preocupações que seriam retomadas em vários outros estudos nas décadas seguintes: o de Barroso e Mello (1975a) sobre o acesso das mulheres ao ensino superior no Brasil e o de Bruschini (1978) a respeito da inserção das engenheiras, enfermeiras e professoras no mercado de trabalho. Outros artigos sobre a baixa participação das mulheres no desenvolvimento científico nacional, publicados na revista Ciência e Cultura no mesmo ano, chamaram a atenção para as desigualdades de oportunidades entre homens e mulheres (Barroso e Mello, 1975b e Barroso, 1975).

\section{Cadernos Pagu: emergência e consolidação do campo nos noventa}

No final dos setenta e durante a década de oitenta, muitas análises sobre a inserção das mulheres no mercado de trabalho revelaram as assimetrias de gênero no que se refere à qualificação, à remuneração $e$ às oportunidades profissionais. Mas, a emergência do campo gênero e ciências propriamente dito seria 
marcada no final dos anos noventa pela iniciativa pioneira da revista Cadernos Pagu que publicou, em 1998, um número temático intitulado Gênero, Tecnologia e Ciência. Nele, a editora convidada, Elizabeth Bortolaia Silva, afirma que trata-se da "primeira publicação em língua portuguesa que contempla a conexão entre estes temas" (Silva,1998:5).

Esse número contém várias contribuições estruturadas em cinco tópicos: tecnologias do lar; tecnologias de reprodução; tecnologias de informática e serviços; tecnologias de produção; ciência. A maior parte dos artigos aborda os impactos das tecnologias sobre diferentes aspectos da vida das mulheres. Destacarei aqueles que foram incluídos no último tópico, pois se vinculam mais diretamente aos objetivos deste artigo. Léa Velho e Elena Léon (1998) analisam dados quantitativos sobre a participação das mulheres no corpo docente e na produção científica, de quatro institutos da Unicamp, Física, Química, Biologia e Ciências Sociais, de 1986 a 1993. As autoras destacam sua baixa representatividade, principalmente em carreiras de maior status e nos postos mais avançados.

O estudo de Maria Margaret Lopes (1998) sobre gênero e história das ciências naturais no Brasil se remete às distintas abordagens da área: estudos sobre mulheres cientistas (biografias, trajetórias), abordagens de gênero, perspectivas feministas sobre a exclusão de gênero na construção do pensamento científico moderno. Uma das conclusões importantes do texto afirma que

diferentemente da tradição norte-americana, $e$ das primeiras décadas do século no Rio de Janeiro, em que mulheres naturalistas e engenheiras tiveram um papel profissional e político atuante, os movimentos feministas desde o final da década de 70, no Brasil, não incorporaram ou geraram qualquer tipo de contingente expressivo de mulheres que se dedicassem ou viessem a se dedicar às ciências naturais e exatas. É certo que o número de mulheres nessas carreiras aumentou, mas isso não significou qualquer mudança nas ciências, nem tampouco a 
Temáticas prioritárias no campo de gênero e ciências no Brasil

criação de tradições de análise "engendradas" sobre as ciências (Lopes, 1998:364).

Lúcia Tosi (1998:369) aborda o contexto da revolução científica do século XVII, relacionando-a com a caça às bruxas e o surgimento da ciência moderna. Apesar das dificuldades enfrentadas pelas mulheres, a autora ressalta que elas "participam ativamente desse movimento, o que desperta as críticas e o escárnio da parte de diversos autores". Referindo-se, dentre outras, às ironias de Molière, o texto conclui que as mulheres que atuaram na Química, Física, Astronomia e Matemática, eram "relegadas a posições secundárias e sua produção permanece muitas vezes ignorada ou obliterada".

A pesquisa de Clevi Elena Rapkiewicz (1998) analisa as variações da divisão do trabalho entre os gêneros nas diferentes profissões e ocupações na área da informática no Brasil entre 1986 e 1997. A autora conclui que a participação das mulheres vem aumentando no campo de analistas e programadores, ainda que lentamente, problematizando assim o argumento tradicional relativo à sua incompetência técnico-científica.

Em 2000, a revista Cadernos Pagu publica um segundo número temático organizado por Maria Margaret Lopes, intitulado Gênero, ciências, história. Os artigos debatem temas candentes: Ilana Löwy problematiza o ideal de universalidade da ciência à luz das contribuições dos estudos sobre a historicidade do conhecimento e dos estudos de gênero; Maria Teresa Citeli revisa a literatura inglesa dos estudos sociais da ciência e dos estudos feministas sobre a ciência para refletir sobre as tendências do debate entre as ciências naturais e esses campos de estudos.

As demais contribuições problematizam a tardia, lenta $e$ complexa inserção das mulheres no campo científico, destacando o papel das pioneiras, a partir da análise de alguns casos que ilustram a luta pela superação dos preconceitos e resistências: a participação de Lady Mary Wortley Montangu nas experiências de combate à varíola no século XVIII (Cedeño, 2000); o papel de Maria 
Francisca Gonzaga nas pesquisas do campo da astronomia no México, no mesmo século (Ramírez, 2000); o das viajantes estrangeiras que visitaram o Brasil no século XIX, registrando suas impressões sobre os recursos naturais, a geografia e a cultura, em diários e cartas (Leite, 2000).

$\mathrm{Na}$ sequência, John Dickenson interroga até que ponto Marianne North, viajante inglesa, artista e escritora, poderia ser considerada uma naturalista; Pamela Henson sintetiza o panorama das cientistas na América Latina entre 1900 e 1950, tomando como exemplo a botânica Agnes Chase; Elisabeth Juliska Rago interpreta as conquistas que algumas médicas brasileiras impulsionaram no século XIX. A autora se detém nas trajetórias de Maria Augusta Generoso Estrela, Josefa Águeda Felisbela Mercedes de Oliveira, Ermelinda Lopes de Vasconcellos, entre outras, destacando a sua capacidade de enfrentar os preconceitos para se estabelecer profissionalmente e para ganhar espaço na vida pública. Além desses artigos, o dossiê inclui ainda um texto de Lewis Pyenson sobre George Sarton, historiador da ciência, e sua filha, a escritora May Sarton (2000).

Em 2004, Nara Azevedo, Bianca A. Cortes, Luiz Otávio Ferreira e Magali Romero Sá publicam no mesmo periódico, um artigo sobre a carreira científica de Aída Hassón-Voloch, especialista em química que conseguiu construir uma carreira acadêmica relevante na área da química, tendo realizado boa parte da sua formação no exterior e atuado de modo marcante no Instituto de Biofísica. O estudo é o resultado de uma pesquisa mais ampla, que tenta recuperar a trajetória das cientistas que atuaram no Instituto Oswaldo Cruz, no Museu Nacional e no Instituto de Biofísica, localizados na cidade do Rio de Janeiro, no período entre 1939 e 1968.

Em 2006, a revista continua atualizando o debate, publicando seu terceiro número sobre o tema. Nele constam várias contribuições de autores/as nacionais e estrangeiras relevantes para o campo, reunidas no Dossiê Gênero na Ciência, organizado também por Maria Margaret Lopes. Esse número inclui a tradução 
Temáticas prioritárias no campo de gênero e ciências no Brasil

de um célebre artigo de Evelyn Fox Keller (2006) no qual são discutidas mudanças significativas que ocorreram no âmbito da Biologia nas últimas décadas, relacionando essas mudanças com as ações políticas feministas e com a entrada de feministas nas pesquisas biológicas; em seguida (num trabalho referido anteriormente) Maria Margaret Lopes (2006a) dá continuidade às suas reflexões sobre o gênero no campo da História das Ciências, revelando vários aspectos teóricos relativos à construção e diversificação das áreas gênero $e$ ciências, gênero em ciências e estudos feministas da ciência, assinalando suas especificidades e entrelaçamentos.

Nesse mesmo número - cadernos pagu nº 27 (2006) -, Carla Giovana Cabral (2006a) critica a neutralidade científica e o determinismo tecnológico, defendendo o conhecimento dialogicamente situado; Apen Luiz Martinez analisa as trajetórias de duas importantes arqueólogas no México no início do século XX; Susan Garcia interpreta a participação das mulheres nas atividades acadêmicas na Argentina no mesmo período; Lina Faria se refere à situação das educadoras sanitárias e das enfermeiras no Brasil; Nara Azevedo e Luís Otávio Ferreira caracterizam a educação e os processos de profissionalização das mulheres entre as décadas de 1920 e 1940; Juliana Schwartz et alii abordam o papel desempenhado pelas pioneiras na informática; Neide Mayumi Osada e Maria Conceição da Costa refletem sobre os preconceitos e obstáculos enfrentados por aquelas que atuam na área da biologia molecular.

Finalmente, Hildete Pereira de Melo e André Barbosa Oliveira analisam a produção científica das mulheres a partir dos dados disponíveis na base de dados da Scientific Eletronic Library Online (Scielo) e no Diretório dos Grupos de Pesquisa do CNPq. Os dados obtidos na Scielo foram levantados entre outubro de 2005 e janeiro de 2006, num total de 147 periódicos. Entre outros resultados importantes, os autores concluem que há uma alta concentração de artigos da área da saúde (44,0\% em 2005), porque essa área hospeda um número maior de periódicos. Identificam também um aumento do número de mulheres nos 
grupos de pesquisa, chegando a 50,0\% na área das Ciências da Saúde e das Ciências Biológicas.

Constatam que a participação das mulheres

ainda permanece marcada pelo estereótipo do papel dos "cuidados", escolhem as áreas vinculadas à educação, saúde e a assistência social. Os homens, seguindo no rastro do papel definido socialmente para o sexo masculino, buscam a aventura do descobrimento dos campos científicos como a engenharia, ciências exatas e da terra e as agrárias. Eles também são aprisionados no seu papel, mas numa concentração inferior a encontrada para as mulheres. Estas são em torno de $44 \%$ das pesquisadoras apenas nas áreas das ciências humanas e da saúde. Por sua vez, eles em engenharia e ciências exatas e da terra são aproximadamente $35 \%$ do total de pesquisadores (Melo e Oliveira, 2006).

Em número mais recente, Elza Vasconcellos e Sandra Brisolla (2009) investigam o desempenho das mulheres no estudo e no trabalho científico na Unicamp, assinalando

a inexistência de diferenças reais por sexo na capacidade de aprendizado e na dedicação dos alunos nas carreiras que se consideram "masculinas", que incluem as ciências exatas e tecnológicas ou engenharias.

As autoras destacam que

na grande maioria dos cursos as alunas têm apresentado melhores coeficientes de rendimento que seus colegas nos mesmos cursos. Por esse motivo, o pouco interesse das vestibulandas por cursos dessa natureza só é explicável por hábitos culturais e preconceitos que se enraizaram na forma diferenciada com que se criam as meninas e os meninos (id.ib.:215). 
Temáticas prioritárias no campo de gênero e ciências no Brasil

Tem-se, portanto, um total de 24 artigos publicados entre 1998 e 2009, sendo dezoito elaborados por pesquisadoras/es brasileiras/os vinculadas/os a diferentes instituições do país; três sobre a situação em outros países (Ramírez, 1998; Sedeño, 2000; Martinez, 2006); dois de autores estrangeiros sobre cientistas estrangeiras que viajaram pelo Brasil (Dieckson, 2000; Henson, 2000); um de pesquisador estrangeiro sobre cientistas estrangeiras (Pyenson, 2000), além de duas traduções (Lowy, 1998 e Fox Keller, 2006).

\section{Ampliação do campo no início do milênio: a contribuição do GeTec/CEFET e do PPGTE/UTFPr, além de outras fontes}

Em 2005, as discussões do campo se enriqueceriam mais ainda com a criação de duas publicações: os Cadernos de Gênero e Tecnologia do Grupo de Estudos e Pesquisas sobre Relações de Gênero e Tecnologia (GeTec), do Centro Federal de Educação Tecnológica (CEFET/Paraná) e a Revista Tecnologia e Sociedade do Programa de Pós-Graduação em Tecnologia (PPGTE), após a transformação do CEFET em Universidade Tecnológica Federal do Paraná. ${ }^{4}$

Aqui não foram incluídos artigos publicados em outras fontes e/ou que desenvolvem temáticas muito semelhantes, relatos de oficinas e de eventos; tampouco artigos sobre a situação em outros países e também sobre educação infantil. Estes últimos, sem dúvida, mereceriam estudos a parte.

No primeiro número dos Cadernos, publicado em março de 2005, Rocha e Carvalho abordam os sistemas de informação e as questões relacionais de gênero no âmbito dos produtores $e$ usuários. Nas conclusões, as autoras destacam que não encontraram diferenças significativas de gênero, faixa etária $e$ etnia no que se refere ao uso e manuseio das tecnologias. Esse número inclui também os resultados de uma análise comparativa

${ }^{4}$ Essas publicações estão hospedadas em www.ppgte.ct.utfpr.edu.br/. Os Cadernos, de 2005 a dezembro de 2008, e a Revista, de 2005 a 2009, foram consultados, no decorrer do mês de novembro de 2010. 
sobre a participação das mulheres nos cursos técnicos na Alemanha e Brasil (Munder et alii, 2005).

No segundo número, Ono e Carvalho (2005) discutem as interferências do gênero sobre o design industrial de produtos, enquanto Casagrande et alii (2005a) analisam a proporção de homens $e$ mulheres entre calouros $e$ formandos nos cursos de engenharia do CEFET.

$\mathrm{O}$ número posterior traz um artigo que aborda as representações de cadetes das primeiras turmas mistas sobre a profissão militar numa Academia das Forças Armadas (Takahaschi, 2005). No quarto, encontram-se três contribuições, sendo uma sobre a história, educação e futuro das mulheres nas escolas de engenharia brasileiras (Cabral, 2005); outra explora a produção de identidades femininas em escolas de engenharias (Saraiva, 2005); por último, Casagrande et alii (2005b) contextualizam a área e sintetizam a trajetória de pioneiras nas ciências naturais.

A sexta edição apresenta a crítica de Aires (2006) às práticas científicas relativas à gestação, parto e puerpério, através da problematização das relações entre tecnologia, história e cultura.

No ano seguinte (2007), esse conjunto seria enriquecido com outras contribuições: Fanny Tabak analisa o papel dos CEFETs e de outras políticas públicas no sentido de favorecer a participação das jovens nos cursos e carreiras técnicas, apesar da persistência de discriminações e estereótipos; Osada e Costa interpretam a participação das cientistas no Projeto Genoma, financiado pela Fundação de Amparo à Pesquisa do Estado de São Paulo (FAPESP), que provocou "importantes mudanças na Biologia Molecular do Brasil", mostrando sua atuação secundária em relação à forte presença masculina nos postos de comando.

Posteriormente, um dos números inclui o artigo de Veronese (2008) sobre a formação em nível superior da tecnologia aeronáutica, explorando as causas do incremento da presença das mulheres nos cursos de graduação em aviação civil.

A Revista Tecnologia e Sociedade publica artigos de várias áreas científicas, incluindo gênero e ciência. Em seu segundo 
Temáticas prioritárias no campo de gênero e ciências no Brasil

número, lançado no primeiro semestre de 2006, consta apenas um artigo da área. Nele, Lombardi (2006a) aborda a evolução da presença feminina nos cursos de graduação em Engenharia, discutindo os padrões de gênero presentes em algumas escolas tradicionais do País.

O terceiro número, lançado no segundo semestre do mesmo ano, se dedica apenas ao gênero, incluindo as seguintes temáticas: crítica feminista aos princípios da objetividade e da neutralidade científica (Cabral, 2006b); interferências do gênero na situação de jovens mestrandas de camadas médias, graduadas em cursos de engenharia, informática, ciências da computação e sistemas de informação (Rocha, 2006); dificuldades encontradas por engenheiros e engenheiras que ocupam posições de comando no Brasil e na França através de comparação de dados obtidos entre 2003 e 2004 (Lombardi, 2006b); diferenciais de gênero entre alunos e alunas dos cursos da área tecnológica no Brasil e na Alemanha (Carvalho, Feitosa e Silva, 2006a); representações de alunos e alunas dos cursos da área tecnológica sobre as relações de gênero e a profissão (Carvalho, Feitosa e Silva, 2006b).

No total, são doze artigos publicados nos Cadernos e seis na Revista, representando, principalmente, a produção científica das pesquisadoras que atuam em instituições localizadas no Sul do país.

Inúmeros artigos sobre o tema foram publicados em outras fontes, também a partir dos noventa, além daquelas já mencionadas. Citando apenas alguns exemplos: Bruschini $e$ Lombardi (1999:9-24) abordaram a situação das mulheres "em carreiras de prestígio", ou seja, nas áreas da medicina, arquitetura, direito e engenharia. As autoras confirmaram a tendência da feminização nos anos 90 e concluíram que os homens se concentravam mais em especialidades mais prestigiadas e melhor remuneradas, que exigiam mais rapidez e capacidade de decisão, enquanto as mulheres atuavam mais nos campos que requerem paciência, persistência e ainda, naqueles que se assemelham mais aos papéis que desempenham no âmbito privado. 
Ao analisar o crescimento da participação das mulheres no campo científico, em alguns cursos de graduação da UFRJ, no quadro de docentes da USP, bem como nos grupos de pesquisas $e$ no quadro de bolsistas cadastrados no $\mathrm{CNPq}$, Jaqueline Leta concluiu, à semelhança de outros estudos, que

\begin{abstract}
apesar da maior participação no sistema brasileiro de C\&T, as mulheres têm chances menores de sucesso e ascensão na carreira: são menos contempladas com bolsas de produtividade do CNPq, estão sub-representadas nos cargos administrativos da UFRJ e entre os acadêmicos da Academia Brasileira de Ciências (2003:276).
\end{abstract}

Em parceria com Grant Lewison (2003), a mesma autora pesquisou a situação das cientistas brasileiras no campo da imunologia, oceanografia e astronomia. Tendo acessado suas publicações no Science Citation Index entre 1997 e 2001 e dados sobre sexo, idade, posição e apoio científico nas bases do CNPq, os autores concluíram que dentre as três áreas citadas, as mulheres estão mais presentes na primeira, participam moderadamente da segunda e menos ainda da terceira. Também recebiam menos apoio em forma de bolsas. Não obstante essas desvantagens, em relação à produção masculina, elas tinham publicado um número semelhante de artigos inclusive com índice também próximo quanto à colaboração internacional.

A pesquisa de Hildete Pereira de Melo e Maria Carolina Casemiro (2004) sobre a composição da Academia Nacional de Medicina e a Academia Brasileira de Ciências, publicada na Revista Rio de Janeiro, revela a baixa participação das mulheres nos anos noventa, apesar da feminização de alguns cursos, evidenciando as resistências à sua absorção em foros institucionais de peso. As autoras destacam que "nos 173 anos vividos pela Academia Nacional de Medicina só cinco mulheres foram eleitas para membro titular, enquanto existiram 612 sócios titulares do sexo masculino" (Melo e Casemiro, 2004:125). 
Temáticas prioritárias no campo de gênero e ciências no Brasil

Observam ainda, que na Academia Brasileira de Ciências, embora o quadro incluísse 571 sócios, apenas 56 eram mulheres, representando $9,8 \%$.

Os membros mais importantes do ponto de vista do reconhecimento científico são os titulares, estes são 334, correspondendo a 58\% dos acadêmicos, mas a taxa de participação feminina cai para 7,8\%, abaixo da participação na própria academia (id.ib.:131).

No caso das entrevistas, vale ressaltar duas publicadas pela Revista Estudos Feministas: uma delas realizada por Miriam Grossi, Carmen Rial e Betina Stefanello com Shirley Malcom (2006), coordenadora dos programas para educação e recursos humanos da American Association for the Advancement of Science (AAAS); a outra, realizada por Cristina Rocha e Miriam Grossi com Eulalia Peréz Sedeño (2009), que exerceu as funções de Diretora da Fundação Espanhola para Ciência e Tecnologia entre 2006 e 2008. Nessas entrevistas, Malcom e Sedeño falam a respeito das suas próprias trajetórias, das políticas de incentivo à inclusão das mulheres nas carreiras científicas que têm sido implementadas nos seus países, bem como da sua participação na construção dessas políticas.

Além dos estudos citados, o periódico publicou mais recentemente o artigo de Eva Blay (2010), o qual se refere a cinco pioneiras que atuaram no Instituto Biológico de São Paulo, destacando a trajetória $e$ as contribuições para o avanço da ciência de Khäte Schwarz, imigrante de origem judaica, especialista em bioquímica de plantas. Em anexo, a autora relaciona os artigos publicados por Schwarz durante os anos $50 e$ 60 em periódicos científicos nacionais.

Chamam a atenção os estudos sobre os impactos da escolarização feminina, por exemplo, as pesquisas de Maria Helena B. Trigo (1994) e de Luís Octávio Ferreira et alii (2008). Tal como no livro de Eva Blay e Alice Beatriz da Silva Lang (2004), 
que será referido no próximo item, Trigo constata a importância da criação, em 1934, da Faculdade de Filosofia, Ciências e Letras da Universidade de São Paulo (USP), para o ingresso das mulheres nas carreiras do ensino superior, consequentemente para as mudanças de valores de gênero dentro e fora dessa instituição.

$\mathrm{O}$ estudo de Ferreira et alii, por sua vez, investiga a crescente escolarização das mulheres no nível superior, a partir dos anos 40, assinalando suas repercussões na institucionalização do conhecimento científico e na profissionalização da pesquisa. A pesquisa analisa os artigos publicados em quatro revistas científicas, entre 1939 e 1969, período no qual pode ser encontrado um índice significativo de artigos elaborados por mulheres.

Embora admita que as dissertações e teses mereçam um estudo a parte, creio que vale a pena mencionar brevemente, ao menos quatro delas: Cristina Rocha (2006) investiga a trajetória das mulheres que atuam em empresas tecnológicas nascentes, incubadas e não incubadas, localizadas em Florianópolis, Santa Catarina. Nessa tese, a autora conclui que apesar dos avanços obtidos em termos de competência e produtividade, elas enfrentam ainda dificuldades para ultrapassar a retaguarda das empresas, pois os homens continuam atuando mais nas funções púbicas de comando e de articulação com o mercado.

A participação das mulheres no campo da engenharia tem sido o foco central em várias análises recentes. Chama atenção a tese de Maria Rosa Lombardi (2005) sobre engenheiras e engenheiros graduadas/os nas décadas de 70, 80 e 90. Nela, a autora caracteriza a feminização da área como uma forma de romper valores tradicionais que a configuravam como reduto masculino; também contribui para o debate no campo analisado a tese de Carla Giovana Cabral (2006) sobre as trajetórias e valores das professoras do Centro Tecnológico da Universidade Federal de Santa Catarina. No âmbito das profissões na área da saúde, destaca-se a tese de Iole Macedo Vanin (2008) sobre o impacto da atuação das médicas, farmacêuticas $e$ odontólogas que ingressaram nos cursos da Faculdade Medicina da Bahia entre 1879 e 1949. 
Temáticas prioritárias no campo de gênero e ciências no Brasil

Apesar dos incontáveis avanços, os estereótipos persistem inclusive no âmbito das lideranças científicas, conforme destaca a pesquisa regional exploratória sobre equidade de gênero na ciência e tecnologia feita por Sylvia Yannoulas (2007). Nela a autora assinala:

ainda que pouco representativas do conjunto de entrevistados e entrevistadas, foi notório descobrir que, após um século de inserção das mulheres nas universidades, continuam circulando estereótipos negativos quanto à capacidade limitada das mulheres para tarefas objetivas e abstratas, dificuldades para a realização de raciocínios científicos, falta de localização espaço-temporal, desvantagem para compreender a lógica científica, etc. (Yannoulas, 2007:7).

\section{Continua a virada: livros e coletâneas entram em cena}

Nesse cenário de debates profícuos, as políticas editorias feministas ampliaram as oportunidades de divulgação, apostando nos livros e coletâneas. Relaciono a seguir, apenas alguns exemplos desses agenciamentos. ${ }^{5} \mathrm{O}$ livro de Fanny Tabak intitulado $O$ Laboratório de Pandora. Estudos sobre a ciência no feminino, publicado em 2002, sem dúvida constitui um marco. Nele, a autora analisa a baixa participação das mulheres nas carreiras de ciência e tecnologia, focalizando a trajetória de duas universidades do Estado do Rio de Janeiro: a Universidade Federal (UFRJ) e a Pontifícia Universidade Católica (PUC-Rio).

A autora constata que, apesar das grandes transformações científicas, tecnológicas e sociais observadas no decorrer do século $\mathrm{XX}$, "as carreiras científicas e tecnológicas não constituem ainda uma prioridade para as estudantes que concluem o segundo

5 Duas publicações que reúnem trabalhos apresentados em eventos foram incluídas como coletâneas: Costa e Sardenberg, 2002; e Secretaria Especial de Políticas para as Mulheres, 2009. 
grau". Assinalando a feminização do campo, Fanny Tabak lembra por exemplo, que na Universidade Federal do Rio de Janeiro em 1977, apenas 35\% do contingente do curso de medicina eram mulheres, enquanto em 1990 a proporção chegava a 62,0\%, quase o dobro. Os dados levantados pela autora nessa instituição mostraram que uma situação semelhante ocorreu na engenharia, outra área tradicionalmente ocupada pelos homens. Os dados evidenciam ainda que o número das mulheres no corpo docente em 1990 ainda era bastante baixo, principalmente nos altos escalões da carreira acadêmica, atingindo apenas $10,0 \%$ entre os titulares em 1991 (Tabak, 2002a:8).

Outra obra que constitui referência na área foi organizada por Ana Alice Costa e por Cecília Sardenberg (2002). Trata-se da coletânea intitulada Feminismo, Ciência e Tecnologia, publicada pela Rede Feminista Norte e Nordeste de Estudos e Pesquisas sobre a Mulher e Relações de Gênero (REDOR) e pelo Núcleo de Estudos Interdisciplinares sobre a Mulher (NEIM). ${ }^{6}$ Essa coletânea aborda vários temas, mas toda a primeira parte é dedicada à crítica feminista à ciência, focalizando a exclusão feminina. Inicialmente Diana Maffia, pesquisadora da Universidade de Buenos Aires, analisa comparativamente dados sobre a participação das mulheres no setor de ciência e de tecnologia no Brasil e na Argentina, apontando para a necessidade de elaboração de políticas de equidade.

Em seguida, Fanny Tabak sintetiza os resultados de suas pesquisas sobre três temas candentes: a participação das mulheres como alunas dos cursos de graduação e dos programas de pósgraduação da Universidade Federal do Rio de Janeiro; a participação das mulheres na Academia Brasileira de Ciências e as

\footnotetext{
6 Essa coletânea "reúne o resultado de conferências e trabalhos apresentados durante o X Encontro da REDOR, realizado conjuntamente ao VII Simpósio Baiano de Pesquisadoras(es) sobre a Mulher e Relações de Gênero em Salvador, em Novembro de 2001, sob a organização e coordenação do NEIM." (essas informações constam no site www.neim.ufba.br, consultado em 19 de abril de 2010).
} 
Temáticas prioritárias no campo de gênero e ciências no Brasil

razões do desinteresse das alunas do segundo grau das escolas do Rio de Janeiro pela ciência.

O artigo de Nadia Regina Loureiro de Barros Lima (2002) analisa os estudos sobre mulher e ciência no Brasil, assinalando as especificidades da presença feminina no campo das ciências e remetendo-as às interferências de gênero; Laura Susana Duque Arrazola (2002), por sua vez, discute os fundamentos teóricometodológicos de uma pesquisa sobre as mulheres na ciência, desenvolvida com o apoio da REDOR e do CNPq.

Ângela Maria Freire de Lima e Souza mostra como os estereótipos de gênero continuam presentes nos estudos biológicos, assinalando os impactos da visão androcêntrica sobre a cultura acadêmica; o ensaio de Cecilia Sardenberg sintetiza vários trabalhos de autoras que têm contribuído para os avanços das epistemologias feministas e defende uma "perspectiva crítica feminista de gênero", comprometida com a liberação das mulheres e de outros segmentos dominados.

Os impactos das novas tecnologias também são abordados nessa coletânea, primeiro no artigo de Maria Helena Santa Cruz, que discute os efeitos perversos da globalização e dos avanços dessas tecnologias sobre o trabalho feminino, e segundo, por Lucila Scavone ao elaborar uma crítica das novas tecnologias reprodutivas, destacando seus efeitos negativos sobre a saúde das mulheres pobres.

O livro de Mariza Corrêa intitulado Antropólogas $e$ Antropologia foi publicado em 2003 e analisa o panorama da História da Antropologia no Brasil, destacando a importância da trajetória de algumas pioneiras no sentido de romper com as estereotipias relativas aos papéis de gênero. A autora se refere a três personagens principais que estiveram à frente de instituições científicas: Emília Snethlage (1868-1929), naturalista alemã que desenvolveu pesquisas de campo através do país, atuando no Museu Paraense Emílio Goeldi e no Museu Nacional do Rio de Janeiro; Leolinda Daltro (1895-1977), indigenista e feminista baiana, que defendeu a alfabetização e a catequização das tribos 
indígenas; e Heloísa Alberto Torres (1895-1977) que se dedicou às políticas públicas indigenistas, à constituição do patrimônio museológico, à formação de jovens pesquisadores, contribuindo para a institucionalização da Antropologia e das Ciências Sociais no país (2003).

No ano seguinte, Eva Blay e Alice Beatriz da Silva Lang publicam o livro intitulado Mulheres na USP: horizontes que se abrem, no qual resgatam as especificidades das trajetórias das primeiras alunas da Faculdade de Filosofia, Ciências e Letras da Universidade de São Paulo (USP) que seguiram a carreira docente na mesma instituição. As autoras lembram que a USP foi fundada em 1934, tendo como eixo essa Faculdade, destinada a formar docentes para o ensino médio num contexto de expansão da industrialização e da urbanização do Estado de São Paulo, o que favoreceu "a entrada consistente de mulheres de vários segmentos da classe média no ensino superior" (Blay e Lang, 2004:12). As entrevistas forma realizadas com Gilda de Mello e Souza, da área de Filosofia; Olga Pantaleão, da História; Alice Canabrava, do campo da Economia e da História; Jandyra França Barzaghi, da Química; Maria Conceição Vicente de Carvalho, da Geografia; e Verônica Rap, da Medicina. Em seus relatos, elas se referem às conquistas profissionais $e$ às inúmeras dificuldades que enfrentaram nas lutas contra os preconceitos de gênero.

Em 2006, Hildete Pereira de Melo, em parceria com Lígia Maria Rodrigues, publica o livro Pioneiras da Ciência no Brasil, reunindo dezenove biografias que sintetizam os percalços $e$ as vitórias das cientistas que atuaram durante a primeira metade do século XX nos seguintes campos: História, Biologia, Química, Psicologia, Física, Matemática, Botânica, Agronomia, Medicina, Economia, Parasitologia.

Ainda nesse ano, uma coletânea organizada por Lucy Woelner dos Santos, Elisa Yoschie Ichikawa e Doralice de Fátima Cargano, intitulada Ciência, Tecnologia e Gênero. Desvelando o feminino na construção do conhecimento, reuniu vários artigos relevantes sobre o tema, incluindo o de Maria Margaret Lopes 
Temáticas prioritárias no campo de gênero e ciências no Brasil

(2006b) sobre a trajetória política e científica da bióloga Bertha Lutz e o de Maria Teresa Citeli sobre a atribuição de diferenças sexuais pela Genética, Química e Anatomia.

Além dessas contribuições, Marta González García e Eulália Pérez Sedeño elaboram uma síntese de temas e de estudos produzidos na América Latina sobre ciência, tecnologia e gênero, assinalando sua heterogeneidade e seus objetivos políticos comuns: "a oposição ao sexismo e ao androcentrismo que se observam nas práticas científicas" (2006:34); Elizabeth Bortolaia Silva questiona o convencionalismo das metodologias científicas, discute a noção de "conhecimentos situados" de Donna Haraway e reflete sobre as maneiras de conhecer que são construídas pelas mulheres no cotidiano (2006:76).

Adelina Pinheiro Santos e Lúcia Tosi resgatam "do esquecimento a contribuição da 'inteligência e da habilidade das mulheres' à ciência e à técnica, a partir da Antiguidade até o fim do período renascentista" (2006:93). Hildete Pereira de Melo e Helena Maria Martins Lastres abordam as relações entre gênero, ciência e tecnologia, a partir da análise dos dados secundários obtidos nas bases de dados do CNPq, relativos aos anos noventa, oferecendo uma visão mais geral da questão.

Entre outras conclusões importantes, as autoras assinalam as seguintes: a) houve um incremento da participação feminina no sistema de bolsas, o qual se explica em virtude do aumento da participação de mulheres na iniciação científica; b) no topo da carreira, ou seja, na categoria pesquisador $1 \mathrm{~A}$, observou-se um incremento da participação das mulheres que em 1990, correspondia a apenas 18,5\%, enquanto em 1999 aumentara para $37,1 \%$; c) apenas nas Humanidades constatou-se um predomínio das mulheres. No entanto esse predomínio parece ter ainda um baixo impacto sobre a distribuição de bolsas, ainda concentradas entre os homens (Melo e Lastres, 2006:134-146).

Finalmente, Luiz Antonio Teixeira e Lucia de La Rocque interpretam 
duas importantes obras literárias do século XIX, Frankenstein, de Mary Shelley, e Dracula, de Bram Stoker, colocando em relevo questões relativas à visão de ciência $e$ sua relação com o gênero dos autores em questão (2006:163).

Aprofundando o seu interesse pela trajetória das cientistas, Elisabeth Juliska Rago (2007) publicou os resultados de uma investigação detalhada sobre a trajetória de Francisca Praguer Froés, médica baiana que se formou na Faculdade de Medicina e Farmácia da Bahia em 1893. Através da análise de vários documentos, a autora mostra que Francisca atuou na área de ginecologia e obstetrícia e se destacou pela sua participação no debate científico, pela defesa dos direitos civis e das ideias feministas e pela crítica à dominação masculina. Além dessas bandeiras, destacou-se por discutir publicamente, questões ligadas à moral e ao sexo, divulgando práticas higiênicas voltadas à saúde das mulheres.

Analisando o papel das mulheres na Marinha, através de pesquisa realizada entre 2005 e 2008, Lombardi (2008) elabora um balanço das dificuldades encontradas por homens $e$ mulheres $e$ contempla a situação das engenheiras navais analisando suas auto-percepções, as diferenças entre as pioneiras $e$ as "mais modernas", as sobreposições dos papéis femininos (funções da maternidade $\mathrm{x}$ atividades na área da engenharia militar), as representações sobre o trabalho. A autora assinala que embora a maioria das entrevistadas tenha realizado estudos de pósgraduação e desenvolva várias atividades especializadas antes apenas desempenhadas pelos homens, continuam enfrentando algumas barreiras. Por exemplo, diferentemente deles, que costumam embarcar em submarinos, navios e aeronaves como atividade de rotina, elas o fazem geralmente para desempenhar atividades técnicas apenas por um determinado período.

Alguns livros se situam no âmbito das análises sobre o gênero na ciência. Na impossibilidade de destacar todos eles, 
Temáticas prioritárias no campo de gênero e ciências no Brasil

refiro-me aqui a apenas três para ilustrar as discussões sobre o corpo e a saúde das mulheres. O livro de Minella (2005), entre outros objetivos, elabora uma análise sociológica das abordagens clínicas sobre esterilização feminina a partir de uma perspectiva de gênero, assinalando as ambivalências dos discursos médicos frente às percepções das mulheres esterilizadas sobre as consequências da laqueadura tubária.

Marlene Tamanini (2009) focaliza as representações de casais heterossexuais e de médico/as a respeito das novas tecnologias conceptivas. Os resultados da pesquisa junto a ambos os segmentos mostram os atravessamentos dos seus discursos, apontam para as ambiguidades da ciência em relação aos resultados do uso das tecnologias e ressaltam o caráter conservador dos valores das instituições médicas a respeito da maternidade e da paternidade. Fabíola Rohden (2009), por sua vez, elabora uma crítica à naturalização das diferenças sexuais operadas estrategicamente pela área de ginecologia no sentido de reforçar e reelaborar as hierarquias de gênero. Através de uma criteriosa pesquisa das teses defendidas nessa área entre 1833 e 1840, encontradas nos arquivos da Faculdade de Medicina do Rio de Janeiro, a autora interpreta os sentidos dos discursos médicos sobre o corpo feminino, revelando os seus vieses, seu sexismo e androcentrismo.

Tania Steren dos Santos (2010) também reflete sobre o campo da medicina, desenvolvendo outras preocupações. Através da realização de entrevistas com médicos e médicas que atuavam em várias especialidades no Hospital de Clínicas de Porto Alegre (HCPA), a autora sonda as interferências de gênero e também da condição geracional na construção da carreira profissional. As conclusões sinalizam que as mulheres dispõem de menos tempo para investir na carreira, dada a sobrecarga representada pelas atividades domésticas. Além disso, enfrentam mais discriminações e ocupam em menor proporção os cargos mais altos da hierarquia profissional.

Finalmente vale ressaltar a publicação do livro que reúne os trabalhos debatidos nas mesas redondas do $2^{\circ}$ Encontro Nacional 
de Núcleos e Grupos de Pesquisa Pensando Gênero e Ciências. ${ }^{7}$ O livro se estrutura em três partes: na primeira, são discutidas as políticas públicas de estímulo à participação das mulheres na pesquisa por parte das agências de fomento em diferentes países; na segunda, são discutidos as dificuldades $e$ os avanços da formação em estudos de gênero e feminismo; na terceira, as políticas de qualificação e o impacto das publicações nessa área. Além das recomendações dos grupos de pesquisa, os anexos incluem também o artigo de Melo (2010) sobre o sistema de concessão de bolsas de pesquisa do $\mathrm{CNPq}$, entre 2001 e 2008. Nele, a autora confirma tendências mostradas em outros estudos: as bolsas de produtividade "são concedidas aos pesquisadores $e$ professores mais qualificados academicamente" sendo distribuídas numa proporção de $22 \%$ para os homens e $11 \%$ para as mulheres, enquanto eles continuam ocupando os postos mais elevados da hierarquia acadêmica.

Desse conjunto composto por treze livros, observo que três deles são coletâneas que incluem debates sobre distintos temas (Costa e Sardenberg, 2002; Santos, Ichikawa e Cargano, 2006; Brasil, 2009); quatro abordam as trajetórias das pioneiras (Corrêa, 2003; Blay e Lang (2004); Melo e Rodrigues, 2006; Rago, 2007); três focalizam a participação das mulheres nas carreiras científicas (Tabak, 2002; Lombardi, 2008; Santos, 2010); enquanto três elaboram críticas aos vieses de gênero nas ciências médicas (Minella, 2005; Rohden, 2009; Tamanini, 2009).

Não obstante os limites deste artigo, a partir dessa imensa variedade de interesses e enfoques, torna-se possível em seguida esboçar uma tentativa de classificação dos temas prioritários, em diálogo com outros intentos já realizados.

7 Evento promovido pela Secretaria de Políticas para as Mulheres, realizado em Brasília em junho de 2009. 


\section{Esboço de uma classificação: construindo e questionando a construção}

Inicialmente, observo que várias tentativas de classificação das pesquisas na área já foram feitas, algumas por autoras bastante conhecidas. Por exemplo, as feitas por Harding $(1996)^{8}$ e Schiebinger $(2001)^{9}$ considerando o contexto anglo-saxão e as de Lopes sobre a área da História das Ciências (1998 e 2006), já referidas nesse trabalho. Lembro ainda da classificação de Cabral $(2008)^{10}$ sobre os trabalhos apresentados nos Seminários

8 Harding identificou cinco tendências de investigação: a) os estudos que apontam as oposições históricas que as mulheres enfrentaram e enfrentam a fim de obter oportunidades educacionais, títulos acadêmicos e atuação semelhantes às dos homens; b) estudos que criticam a biologia, as ciências sociais e suas tecnologias, mostrando o modo como instrumentaram projetos sociais "sexistas, racistas, homófobicos y classistas"; c) estudos que colocaram em dúvida a possibilidade de existência das ciências puras; d) aqueles que reúnem as contribuições da crítica literária, da interpretação histórica e da psicanálise para evidenciar os sentidos simbólicos ocultos nos enunciados e práticas cientificas; e) finalmente, a autora aponta a existência dos estudos que tentam entender "cómo se fundamentan las creencias en las experiencias sociales y el tipo de experiência que serviria de fundamento a las creencias que honramos con la denominación de 'saber'" (1996:20-23).

9 Londa Schiebinger afirma que "a questão do gênero na ciência é enfocada por estudiosos de muitas disciplinas a partir de perspectivas amplamente variáveis. Historiadores estudam as vidas de mulheres-cientistas no contexto de instituições que, por séculos, mantiveram as mulheres à distância; sociólogos enfocam o acesso das mulheres aos meios de produção científica; biólogos examinam como os cientistas estudaram as mulheres; críticos culturais exploram a compreensão normativa de feminilidade e masculinidade; filósofos e historiadores da ciência analisam a influência do gênero sobre o conteúdo e os métodos das ciências" (2001:19-20).

${ }^{10}$ Analisando as pesquisas apresentadas em três edições do Fazendo Gênero (2002, 2004 e 2006), Cabral encontrou "seis sessões de comunicações e duas mesas-redondas relacionando (especificamente) gênero, ciência e tecnologia. Foram apresentados 55 trabalhos, de autoria de 63 pesquisadores - 57 mulheres e seis homens" (2008). Segundo a autora, em 2002 prevaleceram os estudos que relacionavam educação, tecnologia e gênero; em 2004, gênero e tecnologia. Em 2006, a autora constata uma ampliação e maior diversificação tanto da filiação institucional das pesquisadoras, quanto das temáticas abordadas. 
Internacionais Fazendo Gênero 5, 6 e 7. O mapeamento das temáticas prioritárias nos estudos analisados neste artigo, a partir dos noventa, sobre o contexto brasileiro se inspira nessas contribuições e inclui três grandes tendências, excluindo apenas artigos traduzidos e aqueles que embora citados ao longo do texto, apresentam resultados de pesquisas feitas por autoras estrangeiras sobre seus próprios contextos: ${ }^{11}$

1. A primeira delas abrange as análises sobre a participação das mulheres na academia, acesso ao ensino superior, às carreiras científicas, à produção científica e às associações. Nela podem ser incluídos os seguintes estudos: Trigo, 1994; Rapkiewicz, 1998; Bruschini e Lombardi, 1999; Velho e Léon, 1998; Rosemberg, 2001; Tabak, 2002a, 2002b e 2007; Arrazola, 2002; Maffia, 2002; Lima, 2002; Leta, 2003; Leta e Grant, 2003; Melo e Casemiro, 2003; Rocha e Carvalho, 2005; Saraiva, 2005; Azevedo e Ferreira, 2006; Faria, 2006; Rocha, 2006; Lombardi, 2005, 2006a, 2006b e 2008; Cabral, 2005; Takahaschi, 2005; Munder et alii, 2006; Casagrande et alii, 2005a; Melo e Oliveira, 2006; Melo e Lastres, 2006; Osada e Costa, 2006 e 2007; Carvalho, Feitosa e Silva, 2006a e 2006b; Yannoulas, 2007; Veronese, 2007; Ferreira et alii (2008); Melo, 2009; Vasconcellos e Brisola, 2009; Santos, 2010. Temos, portanto, no total, 35 artigos e 4 livros (Tabak, 2002a; Blay e Lang, 2004; Lombardi, 2008 e Santos, 2010).

2. Críticas à ciência, reflexões sobre o gênero na ciência, análises sobre os impactos da ciência e das tecnologias sobre o trabalho e a saúde das mulheres: Tosi, 1998; Lopes, 2000; Santa Cruz, 2002; Scavone, 2002; Souza, 2002; Sardenberg, 2002; Minella, 2005; Ono e Carvalho, 2005; Citeli, 2000 e 2006; Cabral, 2006a e 2006b; Santos e Tosi, 2006; Teixeira e La Rocque, 2006; Silva, 2006; Scavone, 2002; Rohden, 2009; Tamanini, 2009. Nesse caso, o total corresponde a quinze artigos e três livros (Minella, 2005; Rohden, 2009 e Tamanini, 2009).

\footnotetext{
${ }^{11}$ Os estudos citados e não incluídos são os seguintes: Sedeño, 2000; Lowy, 2000; Pyenson, 2000; Ramirez, 2000; Fox Keller, 2006; Garcia, 2006; Martinez, 2006; Teixeira e La Rocque, 2006.
} 
Temáticas prioritárias no campo de gênero e ciências no Brasil

3. História e trajetórias de cientistas e viajantes: Lopes, 1998 e 2006; Leite, 2000; Dieckenson, 2000; Henson, 2000; Rago, 2000 e 2007; Corrêa, 2003; Azevedo et alii, 2004; Aires, 2005; Cabral, 2005 e 2006; Casagrande et alii, 2005; Melo e Rodrigues, 2006; Azevedo, Cortes e Ferreira, 2004; Santos e Tosi, 2006; Schwartz et alii, 2006; Rial, Grossi e Lima, 2006; Vanin, 2008; Rocha e Grossi (2009); Blay (2010). Aqui temos vinte e um estudos, sendo três entrevistas (Azevedo et alii; Rial, Grossi e Lima, 2006; Rocha e Grossi, 2009), três livros (Corrêa, 2003; Melo e Rodrigues, 2006; Rago, 2007), duas teses e treze artigos.

Vários comentários podem ser feitos sobre os limites dessa tentativa de classificação. ${ }^{12}$ Em primeiro lugar, vale lembrar que embora a pesquisa não tenha sido exaustiva, tentei garantir que fosse representativa, incluindo principalmente, veículos, instituições e autor@s que têm sido constantes na divulgação do campo. Isto significa, conforme foi dito na introdução, que outros trabalhos estão sendo analisados e poderão ser incluídos na próxima etapa desta pesquisa. Em segundo lugar, as grandes linhas temáticas, conforme frisei, não são estanques, há sobreposições entre elas e a classificação destacou apenas aquilo que pareceu prioritário nos estudos. Em terceiro, reconheço que cada tendência mereceria um estudo à parte e cada uma delas poderia ser subdividida de acordo com a adoção de outros critérios teóricos e metodológicos.

Por último, vale lembrar, conforme anunciamos na introdução, que essa tipologia tem caráter preliminar, focaliza apenas os temas prioritários nas pesquisas analisadas na intenção de proporcionar uma visão geral do campo. Espera-se que a partir dela, em outros trabalhos, seja possível refletir sobre vários aspectos. Por exemplo, as vinculações entre esses estudos e as obras de referência no plano do debate internacional; as distinções entre os tipos de estudo, do ponto de vista das metodologias

\footnotetext{
${ }^{12}$ Não foram incluídos neste artigo vários trabalhos apresentados (alguns ainda não publicados), em alguns eventos importantes, por exemplo, na série Congressos Ibero-Americanos de Ciência, Tecnologia e Gênero, cuja oitava edição ocorreu em Curitiba, em 2009.
} 
adotadas, identificando os quantitativos, os qualitativos e os qualiquantitativos, e observando-se as especificidades, inclusive daqueles que abordam as representações sociais e científicas sobre as diferenças de gênero; os contextos das investigações, assinalando-se as características dos estudos sobre a presença de mulheres na comunidade científica, (ou seja, nas academias, na liderança de grupos de pesquisa, como bolsistas de produtividade, etc.) e daqueles sobre a presença delas em determinados grupos profissionais (por exemplo, na medicina, nas engenharias, forças armadas, matemática, etc.).

Apesar de seus limites, essa classificação evidencia que de um total de setenta e oito trabalhos, a metade se inclui na primeira grande linha ou tendência temática, dezoito na segunda e vinte $e$ um na terceira. A prevalência da primeira tendência talvez se explique em razão de vários fatores, por exemplo, o alto potencial explicativo dos temas abordados nesses estudos; a atração exercida pelo visível incremento do acesso e da permanência das mulheres no campo científico, inclusive em áreas antes prioritariamente masculinas; $e$, ainda, as relativas facilidades de acesso às informações sobre os contextos atuais. É provável que tal prevalência se explique também em virtude da influência da formação empírica das pesquisadoras, bem como de outros fatores a serem pesquisados.

A largada nos anos noventa e a consolidação na entrada do milênio, por sua vez, talvez possam ser explicadas tanto em decorrência das influências do debate internacional, como de um avanço sem precedentes da incorporação dos achados científicos $e$ das tecnologias à vida cotidiana a nível mundial.

Entre 2000 e 2010, coincidindo com o ponto de vista de Cabral (2008), observa-se uma diversificação maior dos temas, de autoras, instituições e editoras envolvidas, embora as publicações, pelo menos aparentemente, tenham permanecido mais concentradas em alguns veículos. 
Temáticas prioritárias no campo de gênero e ciências no Brasil

\section{Considerações finais: raça/etnia, até quando será uma lacuna?}

Em linhas gerais, considero que os avanços representados pelos estudos analisados são simultaneamente teóricos, metodológicos e políticos. Saltam aos olhos a riqueza e o refinamento dos enfoques e dos procedimentos. O debate com a literatura nacional e internacional, a realização de levantamentos e análises de dados secundários, pesquisas documentais, pesquisas empíricas sobre carreiras específicas têm proporcionado inúmeras possibilidades de interpretação a respeito das temáticas abordadas.

Não obstante os avanços, a revisão da literatura realizada até o momento sinaliza que, no âmbito das interseções, quatro aspectos merecem ser destacados: primeiro, no geral, no que se referem às assimetrias, os estudos têm enfatizado mais claramente as de gênero (entre homens e mulheres). Segundo, as pesquisas empíricas têm contemplado com certa frequência as interseções entre gênero e gerações, através da análise de dados agregados por faixa etária. Por exemplo, as pesquisas de Rocha e Carvalho (2005); Melo e Casemiro (2004); Melo e Lastres (2006); Santos (2010), entre outras. Terceiro, em algumas pesquisas empíricas são referidas informações sobre a condição socioeconômica das mulheres analisadas (Lombardi, 2005; Santos, 2010, por exemplo). Referências a essa condição também são encontradas naquelas que recuperam as trajetórias das cientistas pioneiras (por exemplo, Lopes, 2006b; Rago, 2000 e 2007).

O quarto aspecto destacado é a ausência, entre os estudos abordados, de análises que coloquem as questões étnicas no centro do debate, embora Rocha e Carvalho (2005), por exemplo, tenham contemplado o quesito cor, entre outros relevantes. Os resultados obtidos sugerem que a crítica à ciência formulada nos estudos analisados está centrada no androcentrismo e no sexismo, invisibilizando, de algum modo, o racismo. Chama a atenção que não se problematize, por exemplo, o fato de que as cientistas pioneiras sejam, em geral, brancas e oriundas de famílias de imigrantes europeus. Reconheço, com base em vários estudos, 
que as dificuldades para ingressar no ensino formal $e$ mais especificamente, no nível superior, atingiram durante séculos, as mulheres em geral, sem distinção de classe e de raça/etnia. Admito também que mudanças significativas só começaram a ocorrer no Brasil, a partir dos anos 30, favorecendo amplos contingentes de mulheres. No entanto, considero que a baixa presença de mulheres não brancas, no contexto contemporâneo, evidencia claramente que o seu acesso às carreiras científicas tem sido mais difícil, principalmente em algumas áreas de maior prestígio, requerendo, por isso mesmo, em tempos atuais a implementação de políticas de ação afirmativa.

A pesquisa de João Bosco Hora Góis (2008) constitui uma das exceções, por isso mesmo não foi incluída na classificação proposta. O autor analisa os dados do Censo Étnico-Racial da Universidade Federal Fluminense (UFF) de 2003. Observando a situação em todos os cursos, afirma que "do corpo discente feminino da UFF, em 2003, as negras representavam $32,42 \%$ das alunas $(27,37 \%$ de pardas e $5,05 \%$ de pretas) contra $67,58 \%$ de brancas". Entre as conclusões principais, o autor assinala que elas ingressam na universidade

com menor capital cultural, possivelmente em decorrência da menor herança escolar familiar. Além disso, elas apresentam uma maior tendência a associarem estudo $e$ trabalho nos diferentes níveis educacionais com todas as implicações negativas que isso traz. Outrossim, tendem a completar o ensino médio e fundamental em escolas públicas com maior frequência, possuem rendimento médio familiar menor e moram em cidades mais empobrecidas.

Segundo o autor, esses fatores

contribuem para que elas tendam a ingressar no ensino superior em cursos de menor valoração social, o que por sua vez, possivelmente determina uma remuneração profissional futura mais modesta (2008:764). 
Temáticas prioritárias no campo de gênero e ciências no Brasil

Os cursos aos quais Góis se refere são Pedagogia e Serviço Social.

Além dessa iniciativa, observo que o debate sobre a questão étnica vem ocupando um lugar destacado nas pesquisas sobre acesso ao ensino superior no contexto das ações afirmativas. Exemplos desse enfoque são os estudos de Rosemberg e Andrade (2008), sobre estudantes e candidatos/as ao Programa Internacional de Bolsas de Pós-Graduação da Fundação Ford no Brasil, em que os autores discutem várias interpretações relativas à participação feminina no ensino superior e na pós-graduação, e o de Weller e Silveira (2008) sobre a trajetória de jovens negras na Universidade de Brasília.

No caso dos estudos que se baseiam em fontes secundárias, é provável que@s pesquisador@s tenham enfrentado dificuldades para obter informações nas bases de dados consultadas. Entendo porém, que essa falta resulta não apenas dos vieses daquel@s que organizam essas bases, mas da falta de pressão política das próprias pesquisadoras do campo. Por isso mesmo, uma das recomendações principais deste estudo aponta no sentido não apenas da realização de pesquisas e do fomento do debate, mas de agenciamentos políticos capazes de promover, simultaneamente, a equidade de gênero e o equilibrio entre as etnias. ${ }^{13}$

Do ponto de vista teórico-metodológico, insisto em sugerir que uma avaliação mais crítica do perfil das cientistas, necessitaria articular gênero e raça/etnia de um modo mais enfático, no intuito de relacioná-los de uma maneira mais crítica com os demais marcadores da diferença (classes e gerações) dadas as interferências das sobreposições desses eixos no acesso, permanência $e$ ascensão das mulheres nas carreiras acadêmicas $e$ científicas. Desse modo, estariam criadas as condições para fazer

\footnotetext{
${ }^{13}$ Por exemplo, considero que valeria a pena pressionar os órgãos de fomento à pesquisa e às associações científicas, no sentido da inclusão do quesito cor, esclarecendo-se que o seu preenchimento deve ser feito de modo voluntário. Assim, mesmo dentro de certos limites, seria possível obter informações mais claras e atuais sobre o assunto.
} 
emergir uma quarta tendência temática, além das três encontradas neste estudo.

A análise da bibliografia consultada sugere também que é possivel refletir sobre os avanços obtidos em termos de etapas: da década de 90 até o momento, parece que se cumpriu a primeira delas, representada pelos estudos que se dedicaram a visibilizar o papel das mulheres na ciência. Na virada do milênio se ampliaram as chances de diversificação e de divulgação institucionais. A partir dos avanços obtidos nessa fase, creio que se tornará possível evidenciar, na presente etapa, de modo mais enfático, que uma coisa é a disparidade entre homens e mulheres no campo científico. Outra coisa é a disparidade entre elas. Ao cumprir esse requisito, creio também que o campo gênero e ciências entraria, mais claramente, na mesma rota dos deslocamentos do sujeito que vêm sendo empreendidos pelas teorias feministas no sentido de romper com a unidade da categoria mulher. A compreensão das interseções entre gênero e raça/etnia, que me parece, tem sido pouco explorada em termos de análise, constitui sem dúvida um grande desafio teórico, metodológico e político a ser enfrentado.

Para concluir, esclareço que a motivação deste artigo nasceu do meu contato com duas obras sobre cientistas negras norteamericanas. Uma delas, organizada por Winifred Warren, intitulada Black Women Scientists in the United States (1999), inclui cem biografias de mulheres que superaram inúmeras dificuldades e atuaram com êxito em áreas de ponta no contexto da pesquisa norte-americana. Outra, escrita por Diann Jordan, sugestivamente intitulada Sisters in Science: Conversations with Black Women Scientists on Race, Gender, and Their Passion for Science (2006), reúne relatos emblemáticos de dezessete pesquisadoras negras que construíram sólidas carreiras nas áreas de ciências, matemática e engenharias.

Sendo, provavelmente, uma das poucas afrodescendentes que construíram uma carreira acadêmica na área de Sociologia no Brasil, e tendo atuado nos últimos vinte e cinco anos, numa universidade pública localizada no sul do país - na qual tive, ao 
Temáticas prioritárias no campo de gênero e ciências no Brasil

longo de todos esses anos, apenas três alunos negros, todos africanos -, ao ler esses livros, não pude deixar de me fazer algumas questões: afinal, se um dia resolvesse pesquisar sobre cientistas pioneiras no Brasil, focalizando as mulheres não brancas, qual seria o resultado? Será que ficaria diante de páginas em branco ou traria à tona algumas surpresas? E se resolvesse pesquisar sobre a participação delas no contexto atual, qual seria a sua proporção em relação às demais e quais seriam os campos e instituições nos quais sua presença é mais marcante? Este artigo nasceu tanto do medo das respostas a essas questões, quanto da esperança de que algum equilíbrio racial e étnico possa ser encontrado no futuro próximo também entre as cientistas.

\section{Referências bibliográficas}

AIRES, Maria Juracy. Gestação, Parto e Puerpério, uma discussão sobre tecnologia, história e cultura. Cadernos de Gênero e Tecnologia (6), Curitiba-Pr, Editora do CEFET/PR, 2006, pp.35-33.

ARrAzola, Laura Suzana Duque. Ciência e Crítica Feminista. In: Costa, Ana Alice e SARDENBERG, Cecilia. (orgs.) Feminismo, Ciência e Tecnologia. Salvador, REDOR/NEIM/UFBA, 2002, pp.67-76.

AzEVEDO, Nara et alii. Gênero e Ciência: a carreira científica de Aída HassónVoloch. Cadernos Pagu (23), Campinas-SP, Núcleo de Estudos de Gênero - Pagu/Unicamp, 2004, pp.356-387.

AzEVEDO, Nara e FERREIRA, Luiz Otávio. Modernização, políticas públicas e sistema de gênero no Brasil: educação e profissionalização feminina entre as décadas de 1920 e 1940. Cadernos Pagu (27) Campinas-SP, Núcleo de Estudos de Gênero - Pagu/Unicamp, 2006, pp.213-354.

Azevedo, Nara et alii. (orgs.) História, Ciências, Saúde - Manguinhos (15), Rio de Janeiro, Suplemento 0, 2008.

BARROSO, Carmen Lúcia e Mello, Guiomar N. de. O acesso da mulher ao ensino superior brasileiro. Cadernos de Pesquisa (15), São Paulo, Fundação Carlos Chagas, dezembro de 1975a.

BARROSO, Carmen Lúcia e Mello, Guiomar N. de. A participação da mulher no desenvolvimento científico brasileiro. Ciência e Cultura (27:6), Campinas-SP, 1975b, pp.613-620. 
BARROSO, Carmen Lúcia. Por que tão poucas mulheres exercem atividades científicas? Ciência e Cultura (27:7), Campinas-SP, 1975, pp.703-710.

BLAY, Eva Alterman e LANG, Alice Beatriz da Silva. Mulheres na USP: horizontes que se abrem. São Paulo, Humanitas, 2004.

BLAY, Eva Alterman. Mulheres cientistas: aspectos da vida e obra de Khäte Schwarz. Revista Estudos Feministas (18:2), Florianópolis-SC, 2010, pp.473-489.

BRASIL. Presidência da República. Secretaria Especial de Políticas para as Mulheres. Pensando Gênero e Ciência. Encontro Nacional de Núcleos e Grupos de Pesquisa - 2009, 2010. Brasília, SEPM, 2010.

BourdiEU, Pierre. O campo científico. In: ORTIZ, Renato. (org.) Pierre Bourdieu. Coleção Grandes Cientistas Sociais, n 39. São Paulo, Ática, 1983, pp.122-155.

BRUSCHINI, Cristina. Mulher e Trabalho: engenheiras, enfermeiras e professores. Fundação Carlos Chagas, Cadernos de Pesquisa (27), São Paulo, Fundação Carlos Chagas, 1978.

BRUSCHINI, Cristina e LOMBARDI, Maria Rosa. Médicas, arquitetas, advogadas e engenheiras: mulheres em carreiras de prestígio. Revista Estudos Feministas (7:1), Florianópolis, Centro de Filosofia e Ciências Humanas e Centro de Comunicação e Expressão/UFSC, 1999, pp.9-24.

CABRAL, Carla. As mulheres nas escolas de engenharia brasileiras: história, educação e futuro. Cadernos de Gênero e Tecnologia (1:4), Curitiba, Editora do CEFET/PR, 2005.

. O conhecimento dialogicamente situado: histórias de vida, valores humanistas e consciência crítica de professoras do Centro Tecnológico da UFSC. Tese de Doutorado em Educação Científica e Tecnológica, Universidade Federal de Santa Catarina, 2006.

. Pelas telas, pela janela: o conhecimento dialogicamente situado. Cadernos Pagu (27), Campinas-SP, Núcleo de Estudos de Gênero Pagu/Unicamp, 2006a, pp.63-97.

. Investigando o caráter situado do conhecimento: reflexões sobre epistemologias feministas e educação científica e tecnológica. Revista Tecnologia e Sociedade (3), Curitiba-Pr, PPG em Tecnologia, Universidade Tecnológica Federal do Paraná, 2006b, pp.23-41.

Mapeando e Refletindo a Construção do campo disciplinar "Estudos Feministas da ciência e da tecnologia" no Brasil nos percursos do Fazendo Gênero. Trabalho apresentado no Seminário Internacional 
Temáticas prioritárias no campo de gênero e ciências no Brasil

Fazendo Gênero 8, Corpo, Violência e Poder, Florianópolis, 25 a 28 de agosto de 2008.

Carvalho, Marília Gomes de, Feitosa, Samara e Silva, Valter Cardoso da. Gênero entre estudantes brasileiros/as e alemães/ãs: uma comparação. Revista Tecnologia e Sociedade (3), Curitiba, PPG em Tecnologia, Universidade Tecnológica do Paraná, 2006a. Disponível em: $<$ www.ppgte.ct.utfpr.edu.br/> .

CARVAlHo, Marília Gomes de, Feitosa, Samara e Silva, Valter Cardoso da. Relações de Gênero entre alunos e alunas em uma instituição de educação tecnológica brasileira. Revista Tecnologia e Sociedade (3), Curitiba-PR, PPG em Tecnologia, Universidade Tecnológica do Paraná, 2006b. Disponível em www.ppgte.ct.utfpr.edu.br/

CASAGRANDE, Lindamir S. et alii. Engenheiras no CEFET/PR? levantamento por sexo do número de calouros e formandos nas engenharias. Cadernos de Gênero e Tecnologia (2), Curitiba-PR, Editora do CEFET, 2005a, pp.37-44.

CASAGRANDE, Lindamir S., SCHWARTZ, Juliana, CARVALHO, Marília Gomes de e LESZCZYNSKI, Ana. Mulheres e Ciência: uma relação possível? Cadernos de Gênero e Tecnologia (4), Curitiba-PR, Editora do CEFET, 2005b, pp.31-45.

Citeli, Maria Teresa. Mulheres nas ciências: mapeando campos de estudo. Cadernos Pagu (15), Campinas-SP, Núcleo de Estudos de Gênero Pagu/Unicamp, 2000, pp.39-75.

Genética, Química e Anatomia na atribuição de diferenças sexuais. In: SANTOS, Lucy Woellner dos et alii. (orgs.) Ciência, Tecnologia e Gênero. Desvelando o feminino na construção do conhecimento. Londrina, IAPAR, 2006, pp.233-270.

CORRÊA, Mariza. Antropólogas e antropologia. Belo Horizonte, Editora da UFMG, 2003.

Costa, Ana Alice e SARDEnBerg, Cecilia. (orgs.) Feminismo, Ciência e Tecnologia. Salvador, REDOR/NEIM/UFBA, 2002.

CREENSHAW, Kimberlé. Documento para o encontro de especialistas em aspectos da discriminação racial relativos ao gênero. Revista Estudos Feministas (10:1), Florianópolis, Centro de Filosofia e Ciências Humanas e Centro de Comunicação e Expressão/UFSC, 2002, pp.171-188.

CRUZ, Maria Helena Santana. Novas Tecnologias e Impacto sobre a Mulher. In: Costa, Ana Alice e SARDENBERG, Cecilia. (orgs.) Feminismo, Ciência e Tecnologia. Salvador, REDOR/NEIM/UFBA, 2002, pp.121-140. 
DICKENSON, John. Marianne North: uma naturalista do século dezenove no Brasil? Cadernos Pagu (15), Campinas-SP, Núcleo de Estudos de Gênero - Pagu/Unicamp, 2000, pp.145-164.

FARIA, Lina. Educadoras sanitárias e enfermeiras de saúde Pública: identidades profissionais em construção. Cadernos Pagu (27), CampinasSP, Núcleo de Estudos de Gênero - Pagu/Unicamp, 2006, pp.173-212.

FERREIRA, Luis Otávio et alii. Institucionalização das ciências, sistema de gênero e produção científica no Brasil (1939-1969). In: História, Ciências, Saúde - Manguinhos, vol. 15, Suplemento 0, Rio de Janeiro, 2008, pp.43-71.

FoX KelLER, Evelyn. Secrets of Life, Secrets of Death: essays on language, gender and science. NewYork/London, Routledge, 1992.

. The Origin, History, and Politics of the Subject Called "Gender and Science". In: JASANOFF, Sheila et alii. (eds.) Handbook of Science and Technology Studies. Thousand Oaks, Sage Publishing, 1995, pp.80-94.

. Making a Difference: Feminist Movement and Feminist Critiques of Science. In: CREAGER, A., LUNBECK, E., SCHIEBINGER, L. (eds.) Feminism in twentieth-century science, technology, and medicine. Chicago/London, The University of Chicago Press, 2001, pp.98-109.

. Qual foi o impacto do feminismo na ciência? Cadernos Pagu (27), Campinas-SP, Núcleo de Estudos de Gênero - Pagu/Unicamp, 2006, pp.13-34.

e LONGINO, Helen. (eds.) Feminism and Science. Oxford, New York, Oxford University Press (Oxford Readings in Feminism), 1996.

García, Marta I. González e SEDEÑo, Eulalia Pérez. Ciência, Tecnologia e Gênero. In: SANTOS, Lucy Woellner dos et alii. (orgs.) Ciência, Tecnologia e Gênero. Desvelando o feminino na construção do conhecimento. Londrina, IAPAR, 2006, pp.31-72.

GARCíA, Susana V. Ni solas ni resignadas: la participación femenina en las atividades científico-academicas de la Argentina en los inicios del siglo XX. Cadernos Pagu (27), Campinas-SP, Núcleo de Estudos de Gênero Pagu/Unicamp, 2006, pp.133-172.

GóIs, João Bosco Hora. Quando raça conta: um estudo das diferenças entre mulheres brancas e negras no acesso e permanência no ensino superior. Revista Estudos Feministas (16:3), Florianópolis, Centro de Filosofia e Ciências Humanas e Centro de Comunicação e Expressão/UFSC, 2008, pp.743-768. 
Temáticas prioritárias no campo de gênero e ciências no Brasil

HaraWAY, Donna. Um Manifesto para os Cyborgs: Ciência, Tecnologia e Feminismo Socialista na Década de 80. In: Hollanda, H. Buarque de. (org.) Tendências e Impasses: o feminismo como crítica da cultura. Rio de Janeiro, Rocco, 1994, pp.243-287.

. Saberes localizados: a questão da ciência para o feminismo e o privilégio da perspectiva parcial. Cadernos Pagu (5), Campinas-SP, Núcleo de Estudos de Gênero - Pagu/Unicamp, 1995, pp.07-42.

HARDING, Sandra. Ciencia y Feminismo. Madrid, Morata, 1996.

HENSON, Pamela. A Invasão da Arcádia: as cientistas no Campo na América Latina, 1900-1950. Cadernos Pagu (15), Campinas-SP, Núcleo de Estudos de Gênero - Pagu/Unicamp, 2000, pp.165-198.

JORDAN, Diann. Sisters in Science: Conversations with Black Women Scientists on Race, Gender, and Their Passion for Science. Indiana, Purdue University Press, 2006.

LEITE, Miriam Lifchitz Moreira. Mulheres viajantes no século XIX. Cadernos Pagu (15), Campinas-SP, Núcleo de Estudos de Gênero - Pagu/Unicamp, 2000, pp.130-143.

LETA, Jacqueline. As mulheres na ciência brasileira: crescimento, contrastes e um perfil de sucesso. Estudos Avançados (17:49), Universidade de São Paulo, 2003, pp.271-284.

e LEWISON, Grant. The contribution of women in Brazilian Science: a case study in astronomy, inmunology and oceanography. Scientometrics (57:3), Heidelberg-Germany, 2003, pp.339-353.

LiMA, Nádia Regina Loureiro de Barros. As Mulheres nas Ciências: o Desafio de Uma Passagem... A Passagem do Privado para o Público. In: CostA, Ana Alice e SARDEnBERG, Cecilia. (orgs.) Feminismo, Ciência e Tecnologia. Salvador, REDOR/NEIM/UFBA, 2002, pp.51-66.

LOMBARDI, Maria Rosa. Perseverança e resistência: a engenharia como profissão feminina. Tese de Doutorado, Faculdade de Educação, Unicamp, 2005.

A engenheira brasileira contemporânea e a contribuição das mulheres nas mudanças recentes no campo profissional. Revista Tecnologia e Sociedade (2), Curitiba-PR, PPG em Tecnologia, Universidade Tecnológica do Paraná, 2006a. Disponível em: $<$ www.ppgte.ct.utfpr.edu.br/>.

Engenheira \& Gerente: desafios enfrentados por mulheres em posições de comando na área tecnológica. Revista Tecnologia e 
Sociedade (3), Curitiba-Pr, PPG em Tecnologia, Universidade Tecnológica Federal do Paraná, 2006b. Disponível em: $<$ www.ppgte.ct.utfpr.edu.br/>.

As mulheres nas Forças Armadas brasileiras: a Marinha do Brasil. São Paulo, Fundação Carlos Chagas, 2008.

LOPES, Maria Margaret. "Aventureiras" nas ciências: refletindo sobre gênero e história das ciências naturais no Brasil. Cadernos Pagu (10), CampinasSP, Núcleo de Estudos de Gênero - Pagu/Unicamp, 1998, pp.345-368.

Sobre convenções em torno de argumentos de autoridade. Cadernos Pagu (27), Campinas-SP, Núcleo de Estudos de Gênero Pagu/Unicamp, 2006a, pp.35-61.

"Vencer barreiras", até quando? Aspectos da trajetória científico-política de Bertha Maria Júlia Lutz (1894-1976). In: SANTOS, Lucy Woellner dos et alii. (orgs.) Ciência, Tecnologia e Gênero. Desvelando o feminino na construção do conhecimento. Londrina, IAPAR, 2006b, pp.203-232.

LöWY, Ilana. Universalidade da ciência e conhecimentos "situados". Cadernos Pagu (15), Campinas-SP, Núcleo de Estudos de Gênero Pagu/Unicamp, 2000, pp.15-38.

MAFFIA, Diana. Críticas feministas à ciência. In: CostA, Ana Alice e SARDENBERG, Cecilia. (orgs.) Feminismo, Ciência e Tecnologia. Salvador, REDOR/NEIM/UFBA, 2002, pp.25-38.

MARTINEZ, Apen Ruiz. Zelia Nuttal e Isabel Ramirez Castañeda: las distintas formas de practicar y escribir sobre arqueologia en el México de inicios del siglo XX. Cadernos Pagu (27), Campinas-SP, Núcleo de Estudos de Gênero - Pagu/Unicamp, 2006, pp.99-133.

Melo, Hildete Pereira de e CASEMIRO, Maria Carolina Pereira. A Ciência no Feminino: uma análise da Academia Nacional de Medicina e da Academia Brasileira de Ciência. Revista Rio de Janeiro (11), Rio de Janeiro, UERJ/Fiocruz, 2004, pp.117-134.

e LASTRES, Helena Maria Martins. Ciência e Tecnologia numa perspectiva de Gênero: o caso do CNPq. In: SANTOS, Lucy Woelner dos et alii. Ciência, Tecnologia e Gênero. Desvelando o feminino na construção do conhecimento. Londrina, IAPAR, 2006, pp.129-160.

e OliveirA, André Barbosa. A produção científica brasileira no feminino. Cadernos Pagu (27), Campinas-SP, Núcleo de Estudos de Gênero - Pagu/Unicamp, 2006, pp.301-331. 
Temáticas prioritárias no campo de gênero e ciências no Brasil

e Rodrigues, Lígia Maria. Pioneiras das Ciências no Brasil. Rio de Janeiro, SBPC, 2006.

. Um olhar de gênero sobre o sistema de concessão de Bolsas de Pesquisa no CNPq - 2001/2008. In: BRASIL. Presidência da República. Secretaria Especial de Políticas para as Mulheres. Pensando Gênero e Ciência. Encontro Nacional de Núcleos e Grupos de Pesquisa - 2009, 2010. Brasília, SEPM, 2010, pp.176-191.

Minella, Luzinete Simões. Gênero e Contracepção. Uma perspectiva sociológica. Florianópolis, Editora da UFSC, 2005.

MotT, M. L. B., DuARTE, Ivomar Gomes e GOMES, Marcela Trigueiro. Montando um quebra cabeça: a Coleção "Universidade de São Paulo" do Arquivo do Estado de São Paulo. Cadernos de História da Ciência, vol. 3, 2007, pp.37-72.

MotT, M. L. B. et alii. Moças e senhoras dentistas: formação, titulação e mercado de trabalho nas primeiras décadas da República. História, Ciências, Saúde-Manguinhos, vol. 15, 2008, pp.97-116.

MotT, M. L. B. et alii. Médicos e médicas em São Paulo e os Livros de Registros do Serviço de Fiscalização do Exercício Profissional (18921932). Ciência \& Saúde Coletiva, vol. 13, 2008, pp. 853-868.

MUNDER, Irmhard et alii. Mujeres y Estúdios Técnicos, conceptos compatibles? Tentativa de una comparación intercultural entre Alemania y Brasil. Cadernos de Gênero e Tecnologia (1), Curitiba-PR, Editora do CEFET, 2005, pp.20-34.

OnO, Maristela Mitsuko e CARVAlHo, Marília Gomes de. Isto é "coisa para mulheres": Gênero e design no desenvolvimento de produtos para a sociedade. Cadernos de Gênero e Tecnologia (2), Curitiba-PR, Editora do CEFET, 2005.

OsADA, Neide Mayumi e COSTA Maria Conceição da. A construção social de gênero na Biologia: preconceitos e obstáculos na biologia molecular. Cadernos Pagu (27), Campinas, Núcleo de Estudos de Gênero Pagu/Unicamp, 2006, pp.279-299.

A Construção da "Nova" Biologia. Relações de Gênero nos laboratórios do Projeto Genoma da FAPESP. Cadernos de Gênero e Tecnologia (11), Curitiba-PR, GeTec/PPGTE/CEFET, 2007, pp.21-34.

PYENSON, Lewis. Eros e Isis, tal pai, tal filha. Cadernos Pagu (15), CampinasSP, Núcleo de Estudos de Gênero - Pagu/Unicamp, 2000, pp.227-248. 
RAGO, Elisabeth Juliska. A ruptura do mundo masculino da medicina: médicas brasileiras no século XIX. Cadernos Pagu (15), Campinas-SP, Núcleo de Estudos de Gênero - Pagu/Unicamp, 2000, pp.199-225.

. Outras falas: feminismo e medicina na Bahia (1836-1931). São Paulo, Annablume/FAPESP, 2007.

RAMíREZ, Aurora Tovar. Ephemeris calculada al Meridiano de México para el año Del Señor de 1757. Por Doña Maria Francisca Gonzaga de el Castillo. Cadernos Pagu (15), Campinas, Núcleo de Estudos de Gênero Pagu/Unicamp, 2000, pp.103-128.

RAPKIEWICZ, Clevi Elena. Informática: domínio masculino? Cadernos Pagu (10), Campinas-SP, Núcleo de Estudos de Gênero - Pagu/Unicamp, 1998, pp.169-200.

RIAL, Carmen, Grossi, Miriam Pillar e LiMA, Bettina Stefanello. Gênero e Ciência, entrevista com Shirley Malcom. Revista Estudos Feministas (14:3), Florianópolis, Centro de Filosofia e Ciências Humanas e Centro de Comunicação e Expressão/UFSC, 2006, pp.695-708.

RochA, Cristina Tavares da Costa. Gênero em Ação: Rompendo o Teto de Vidro? (Novos Contextos da Tecnociência). Tese de Doutorado, Interdisciplinar em Ciências Humanas, Universidade Federal de Santa Catarina, 2006a.

. Expressões do Ciberfeminismo na contemporaneidade. Revista Tecnologia e Sociedade (3), PPG em Tecnologia, Universidade Tecnológica Federal do Paraná, 2006b. Disponível em: $<$ www.ppgte.ct.utfpr.edu.br/>.

e Carvalho, Marília Gomes de. As duas extremidades dos Sistemas de Informação (SI) e as questões relacionais de gênero. Cadernos de Gênero e Tecnologia (1), Curitiba-PR, Editora do CEFET, 2005, pp.9-19.

e Grossi, Miriam. Filosofia, Gênero e Ciência: entrevista com Eulalia Perez Sedeño. Revista Estudos Feministas (17:1), FlorianópolisSC, Centro de Filosofia e Ciências Humanas e Centro de Comunicação e Expressão/UFSC, 2009.

ROHDEN, Fabíola. Uma ciência da diferença: sexo e gênero na medicina da mulher. Rio de Janeiro, FIOCRIZ, 2009.

ROSEMBERG, Fúlvia e ANDRADE, Leandro Feitosa. Ação afirmativa no ensino superior brasileiro: a tensão entre raça/etnia e gênero. Cadernos Pagu (31), Núcleo de Estudos de Gênero - Pagu/Unicamp, 2008, pp.419-438. 
Temáticas prioritárias no campo de gênero e ciências no Brasil

SANTOS, Adelina Pinheiro e Tosi, Lucia. Resgatando Métis. O que foi feito desse saber? In: SANTOS, Lucy Woellner dos et alii (orgs.) Ciência, Tecnologia e Gênero. Desvelando o feminino na construção do conhecimento. Londrina, IAPAR, 2006, pp.91-127.

SANTOS, Lucy Woelner dos et alii (orgs.) Ciência, Tecnologia e Gênero. Desvelando o feminino na construção do conhecimento. Londrina, IAPAR, 2006.

SANTOS, Tania Steren dos. Carreira Profissional e Gênero: trajetória de homens e mulheres na medicina. Porto Alegre, Editora da UFRGS, 2010.

SARDENBERG, Cecília Maria Bacellar. Da Crítica Feminista à Ciência a uma Ciência Feminista. In: CostA, Ana Alice e SARDENBERG, Cecilia. (orgs.) Feminismo, Ciência e Tecnologia. Salvador, REDOR/NEIM/UFBA, 2002, pp.89-120.

SARAIVA, Karla. Fabricando identidades femininas em Escolas de Engenharia. Cadernos de Gênero e Tecnologia (4), Curitiba-PR, Editora do CEFET, 2005.

SCAVONE, Lucila. Impacto das Novas Tecnologias Reprodutivas. In: COSTA, Ana Alice e SARDENBERG, Cecilia. (orgs.) Feminismo, Ciência e Tecnologia. Salvador, REDOR/NEIM/UFBA, 2002, pp.141-151.

SCHARTZ, Juliana et alii. Mulheres na informática: quais foram as pioneiras? Cadernos Pagu (27), Campinas-SP, Núcleo de Estudos de Gênero Pagu/Unicamp, 2006, pp.255-278.

SCHIEBINGER, Londa. O Feminismo mudou a ciência? Bauru, SP, EDUSC, 2001.

SEDEÑO, Eulalia Perez. Institucionalización de la ciência, valores epistêmicos y contextuales: um caso ejemplar. Cadernos Pagu (15), Campinas-SP, Núcleo de Estudos de Gênero - Pagu/Unicamp, 2000, pp.70-102.

SILVA, Elizabeth Bortolaia. Apresentação e agradecimentos. Cadernos Pagu (10), Campinas-SP, Núcleo de Estudos de Gênero - Pagu/Unicamp, 1998, pp.5-6.

Conhecimentos no cotidiano: Situações e Histórias. In: SANTOS, Lucy Woelner dos et alii. (orgs.) Ciência, Tecnologia e Gênero. Desvelando o feminino na construção do conhecimento. Londrina, IAPAR, 2006, pp.73-88.

SouZA, Ângela Maria Freire de Lima e. O Viés Androcêntrico em Biologia. In: Costa, Ana Alice e SARDEnBERG, Cecilia. (orgs.) Feminismo, Ciência e Tecnologia. Salvador, REDOR/NEIM/UFBA, 2002, pp.77-88. 
TABAK, Fanny. O Laboratório de Pandora. Estudos sobre a ciência no feminino. Rio de Janeiro, Garamond, 2002a.

. Estudos Substantivos sobre Mulher e Ciências no Brasil. In: Costa, Ana Alice e SARDEnBERG, Cecilia. (orgs.) Feminismo, Ciência e Tecnologia. Salvador, REDOR/NEIM/UFBA, 2002b, pp.39-50.

. Apesar dos avanços - obstáculos ainda persistem. Cadernos de Gênero e Tecnologia (11), Curitiba-PR, GeTec/PPGTE/CEFET, 2007, pp.9-20.

TAKAHASHI, Emília. A formação militar sob o enfoque das relações de gênero: uma experiência. Cadernos de Gênero e Tecnologia (3), Curitiba-PR, Editora do CEFET, 2005, pp.14-22.

TAMANINI, Marlene. Reprodução Assistida e Gênero. O olhar das ciências humanas. Florianópolis, Editora da UFSC, 2009.

TEIXEIRA, Luiz Antonio e ROCQUE, Lúcia de la. Frankestein de Mary Shelley: a ciência, seus mitos e seus monstros. In: SANTOS, Lucy Woelner dos et alii. (orgs.) Ciência, Tecnologia e Gênero. Desvelando o feminino na construção do conhecimento. Londrina, IAPAR, 2006, pp.161-202.

Tosi, Lúcia. Mulher e Ciência. A revolução científica, a caça às bruxas e a ciência moderna, Cadernos Pagu (10), Campinas, Núcleo de Estudos de Gênero - Pagu/Unicamp, 1998, pp.369-398.

TRIGO, Maria Helena Bueno. A mulher universitária: códigos de sociabilidade e relações de gênero. In: BRUSCHINI, Cristina e SORJ, Bila. (orgs.) Novos Olhares: mulheres e relações de gênero no Brasil. São Paulo, Marco Zero, 1994, pp.89-110.

TuAnA, Nancy. (ed.) Feminism and Science (Race, Gender and Science). Bloomington, Indiana University Press, 1989.

VANIN, Iole Macedo. As damas de branco na biomedicina baiana (18791949): médicas, famacêuticas e odontólogas. Tese de Doutorado em História, Universidade Federal da Bahia, 2008.

VAsConcellos, Elza da Costa Cruz e BRISOlla, Sandra Negraes. Presença feminina no estudo e no trabalho da ciência na Unicamp. Cadernos Pagu (32), Campinas-SP, Núcleo de Estudos de Gênero - Pagu/Unicamp, 2009, pp.215-265.

VELHO, Léa e LEON, Helena. A construção social da produção científica por mulheres. Cadernos Pagu (10), Campinas-SP, Núcleo de Estudos de Gênero - Pagu/Unicamp, pp.309-344. 
Temáticas prioritárias no campo de gênero e ciências no Brasil

VeRONESE, Silvia Mara. Novas Rotas, Novos Vôos: a mulher ocupando espaço na educação e no trabalho. Cadernos de Gênero e Tecnologia (15 e 16), Curitiba-Pr, GeTec/PPGTE/CEFET, 2007, pp.23-39.

WARREN, Winifred. Black Women Scientists in the United States. Bloomington, Indiana Press, 1999.

WeLLER, Wivian e SILVEIRA, Marly. Ações afirmativas no sistema educacional: trajetórias de jovens negras na Universidade de Brasília. Revista Estudos Feministas (16:3), Florianópolis, Centro de Filosofia e Ciências Humanas e Centro de Comunicação e Expressão/UFSC, 2008, pp.931-948.

YanNoulas, Sylvia. Mulheres e Ciência. Série Anis 47, Brasília, LetrasLivres, 1-10, 2007. 